\title{
Air pollution and telomere length: a systematic review of 12,058 subjects
}

\author{
Bing Zhao, Ha Q. Vo, Fay H. Johnston, Kazuaki Negishi \\ Menzies Institute for Medical Research, University of Tasmania, Hobart, Australia \\ Contributions: (I) Conception and design: K Negishi; (II) Administrative support: K Negishi; (III) Provision of study material or patients: B Zhao, HQ \\ Vo; (IV) Collection and assembly of data: B Zhao; (V) Data analysis and interpretation: B Zhao, FH Johnston, K Negishi; (VI) Manuscript writing: \\ All authors; (VII) Final approval of manuscript: All authors. \\ Correspondence to: Kazuaki Negishi, MD, PhD, FACC, FESC, FASE, FAHA. Menzies Institute for Medical Research, University of Tasmania, 17 \\ Liverpool St, Hobart, TAS 7000, Australia. Email: Kazuaki.Negishi@utas.edu.au.
}

\begin{abstract}
Background: Over recent decades, adverse effects of ambient air pollution on the cardiovascular system have been clearly demonstrated. However, the underlying mechanisms are not fully elucidated. Air pollution may accelerates biological aging and thereby the susceptibility to cardiovascular diseases (CVDs). Telomeres are tandem repetitive DNA complexes that play a critical role in maintaining chromosome stability. There are, however, heterogeneities among the reported effects of air pollution on telomere. This study sought to evaluate the existing literature on the association between air pollution and telomere length (TL).

Methods: Two reviewers independently searched on electronic databases including PUBMED, EMBASE, SCOPUS, WEB OF SCIENCE and Ovid. The key terms were "air pollution" and "telomere" without language restriction. Articles relating to tobacco smoke were excluded.

Results: A total of 12,058 subjects from 25 articles remained for final review. All were observational studies: 14 cross-sectional, 6 cohort and 5 case-control studies. Nineteen (76\%) assessed leukocyte telomere length (LTL) of which 15 found associations between air pollution and shorter TL, 2 with longer TL, 1 had mixed results, and a study of patients with type 2 diabetes found non-significant associations with TL. One found longer TL from saliva. The remaining studies were of placental cells, buccal cells or sperm and all reported shorter TL associated with air pollution. Particulate matter (PM) was investigated in 8 articles, and the remainder assessed black carbon (BC), benzene, lead, cadmium and polycyclic aromatic hydrocarbon (PAH). Geographically, 11 studies were conducted in Europe, with 10 in Asia and 4 in North America. While all followed Cawthon's protocol for TL assessment, discordance in the reporting formats did not allow us to perform a quantitative meta-analysis.
\end{abstract}

Conclusions: Most of the studies support the association of shorter TL with air pollution. Uniform reporting format would be warranted for future studies to estimate true effect size of air pollution on TL.

Keywords: Air pollution; telomere length (TL); systematic review

Submitted Mar 27, 2018. Accepted for publication May 22, 2018.

doi: $10.21037 / \mathrm{cdt} .2018 .06 .05$

View this article at: http://dx.doi.org/10.21037/cdt.2018.06.05

\section{Introduction}

Air pollution is a ubiquitous public health issue. Indoor and outdoor air pollution are the $3^{\text {rd }}$ and $9^{\text {th }}$ risk factors for worldwide mortality and morbidity (1). It is estimated that 4.3 million urban people will die prematurely due to outdoor air pollution in 2050, which accounts for $65 \%$ of the total death all over the world (2). Although air pollutants has long been understood to affect the respiratory system, the adverse effects on the cardiovascular system cause mortality impacts that exceed those from lung diseases and cancers $(3,4)$. The impact of both short and 
long term exposure to air pollution on the cardiovascular system has been confirmed by epidemiological studies (4). Long term exposure to air pollutants contributes to the risk of both ischemic and non-ischemic cardiovascular disease (CVD) (5). Acute effects of elevated ambient particulate matter (PM) levels are more likely to occur on people who are elderly or already have CVD, even if this has not been recognized (4). The length of the chromosomal telomere is a biological clock, reflecting the biological aging process of cells. CVD is known clearly as age-related disease and researchers have been working on identifying a biomarker to reflect aging, as people with same chronological age may have different health status (6). Studies have demonstrated that individuals with shorter leukocyte telomere length (LTL) have an increased risk of myocardial infarction $(7,8)$, coronary heart disease (9), heart failure (10), hypertension (11) and stroke (8). One study using Mendelian randomization approach proved causal effect of shorter genetically determined telomere length (TL) on CVD and cancer (12). TL can be a cardiovascular biomarker for biological aging. Until now, inflammatory reactions and oxidative stress are understood as critical mechanisms linking air pollution with related morbidity and mortality (13). These processes also accelerate telomere shortening (6). However, the reported relationships between air pollution and telomeres are inconsistent. Therefore, the aims of this study were to summarize the effects of air pollution on TL through a systematic review of literature, and to identify possible issues, including the factors hampering the quantification of the pooled estimates.

\section{Methods}

We followed the Preferred Reporting Items for Systematic Reviews and Meta-Analysis (PRISMA) guideline when performing our systematic review and meta-analysis (14). Electronic databases including PubMed, Embase, Scopus, Web of Science as well as Ovid (with all resources) were searched for articles that had examined the association between air pollution and TL. There was no restriction to language and study type. "Telomere", "air pollution", "air pollutant", "particulate matter" and related free text terms were used for the search. Search hedges created are listed in the online supplementary material (Supplementary file). The first search was performed on 18 January 2016, and the last search was performed on 16 August 2017.

We followed the US Environmental Protection Agency criteria for ambient air pollutants, such as $\mathrm{PM}$, nitrogen oxides $\left(\mathrm{NO}_{\mathrm{x}}\right)$, carbon monoxide $(\mathrm{CO})$, sulfur dioxide $\left(\mathrm{SO}_{2}\right)$, and ozone $\left(\mathrm{O}_{3}\right)$. There was no restriction to language and no time limit on publication date. We excluded studies of tobacco smoke, animal, cell-line, and genetic studies. Published conference abstracts, reviews, editorials and duplicates were also excluded. The most extensive article was chosen when more than one publication included the same content. When information was insufficient to make a judgment on the eligibility of a study, efforts were made to contact its corresponding author to obtain further information.

Two reviewers (Bing Zhao and Kazuaki Negishi), independently searched for studies and reviewed full-text through screening title and abstract using inclusion and exclusion criteria. A standard protocol was used to extract data from appropriate articles. The information collected included location, publication year, study design, samples size, tissue source, age, sex, participant characteristics, air pollutants and levels, monitoring methods, mean and standard deviation of TL, the outcome of association, and the characteristics of control group.

The Newcastle-Ottawa Quality Assessment Scale for cohort studies (15) was used as a unified standard to assess the quality of included studies. This tool contains eight items with three main components: selection, comparability, and outcome. The number of stars the study obtained represents the assessment results. A maximum of nine stars can be given for each study.

\section{Results}

The systematic search identified 2,151 titles (Figure 1). After removing 425 duplicates, 1,726 records were screened. After title and abstract review, a further 1,665 records were excluded. After full text screening of the 61 remaining articles, 25 articles that examined the relationship between air pollution and TL were finally included in this systematic review.

Table 1 summarizes the characteristics from the 25 articles ( $\mathrm{n}=12,058$ subjects) included in qualitative analysis (16-40). The sample sizes ranged from 14 (24) to 6,796 (40). All were observational studies: 14 cross-sectional (16-18,22-24,26,27,32-35,38,40), 6 cohort $(20,29,30,36,37,39)$ and 5 case-control studies $(19,21,25,28,31)$. All applied Cawthon's protocol based on polymerase chain reaction (PCR) analysis method to measure TL: 19 studies ( $\mathrm{n}=10,568$ subjects) assessed LTL (16,18-20,22-27,30-33,36-40), 2 studies with placenta TL $(17,28), 2$ for buccal cell telomere 


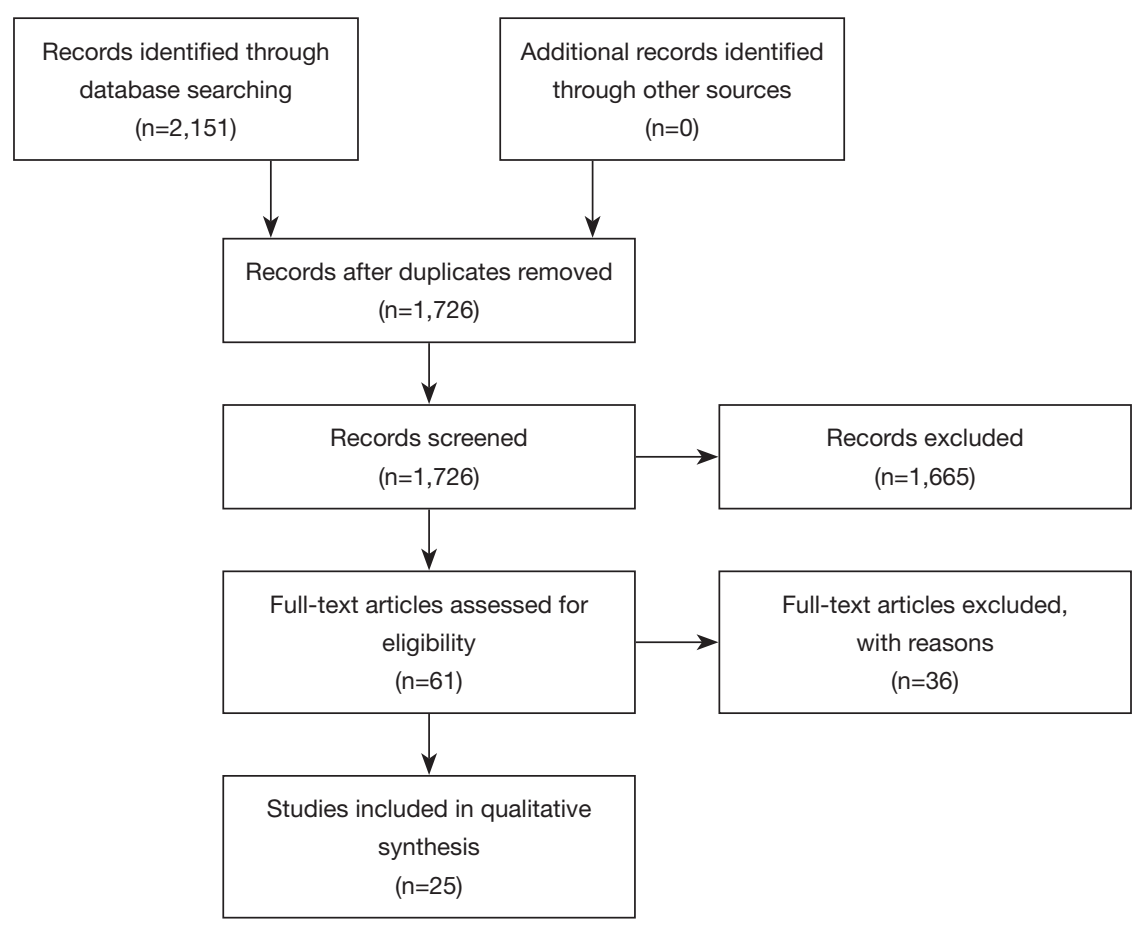

Figure 1 PRISMA flow chart. This flow chart illustrates the selection process for identified articles.

$(21,34)$ and 2 from sperm (29) and saliva (35) respectively (Figure 2). Among two versions of Cawthon's protocols, 6 studies $(16,17,27,33,35,38)$ followed Cawthon's newer version published in 2009 (41), while remaining articles applied the original Cawthon's method (42). Geographically, 11 studies were conducted in Europe $(17,19,20,23,25,26,31-33,35,36)$, with 10 in Asia $(16,18,21,22,27-29,34,38,39)$ and 4 in North America $(24,30,37,40)$. Multiple ethnicities were included: 7,023 Americans, 3,254 Europeans and 1,781 Asians. The comparative groups were those who exposed to filtered air or clean air; and those not exposed to air pollution.

The concentration of airborne PM was investigated in 8 articles $(20,22,33-37,39)$. Seven $(22,33-37,39)$ of these examined the association between $\mathrm{PM}<2.5 \mu \mathrm{m}$ in aerodynamic diameter $\left(\mathrm{PM}_{2.5}\right)$ and $\mathrm{TL}$, and $\mathrm{PM}<10 \mu \mathrm{m}$ in aerodynamic diameter $\left(\mathrm{PM}_{10}\right)$ were reported in 5 articles (20,22,35,36,39). Dioni et al. (20) and Wong et al. (37) used $\mathrm{PM}$ data from multiple sites in factories to calculate the personal exposures. One study included both personal and ambient air pollutants. Small-sized gravimetric samplers were carried by study subjects to measure personal $\mathrm{PM}_{2.5}$ exposure and ambient $\mathrm{PM}_{10}$ data were obtained from the local environmental agency (22). Personal exposure monitors (PEMs) were used in a pilot study (34). Pieters et al. (33), Walton et al. (35) and Ward-Caviness et al. (36) estimated PM level from fixed monitoring sites. Xia et al. (39) measured real-time ambient PM level using an Environmental Dust Monitor, and data for other gaseous pollutants were obtained from governmental monitoring stations.

Urinary metabolite for polycyclic aromatic hydrocarbons (PAHs) of workers were measured as a marker of personal exposure in 4 studies $(18,26,29,31)$, while Lee et al. (24) calculated individual exposure to PAHs via monitoring site and outdoor residential samples. Occupational air pollutants studied included benzene $(16,23)$, toluene $(23,26)$ and welding fumes (25). A study focused on traffic pollutants used the distance from major road and traffic density to estimate the exposure data. Exposure to lead and cadmium was assessed through blood $(32,38,40)$ and placental measurements (28). McCracken et al. (30) estimated the annual ambient black carbon (BC) exposure on elderly veterans based on a spatiotemporal model. One study examined long term effect of indoor air pollution from household fuel combustion on LTL via related questions to assess the pollution level (27).

Of 19 articles examined the association between LTL 
Table 1 Summary of included studies

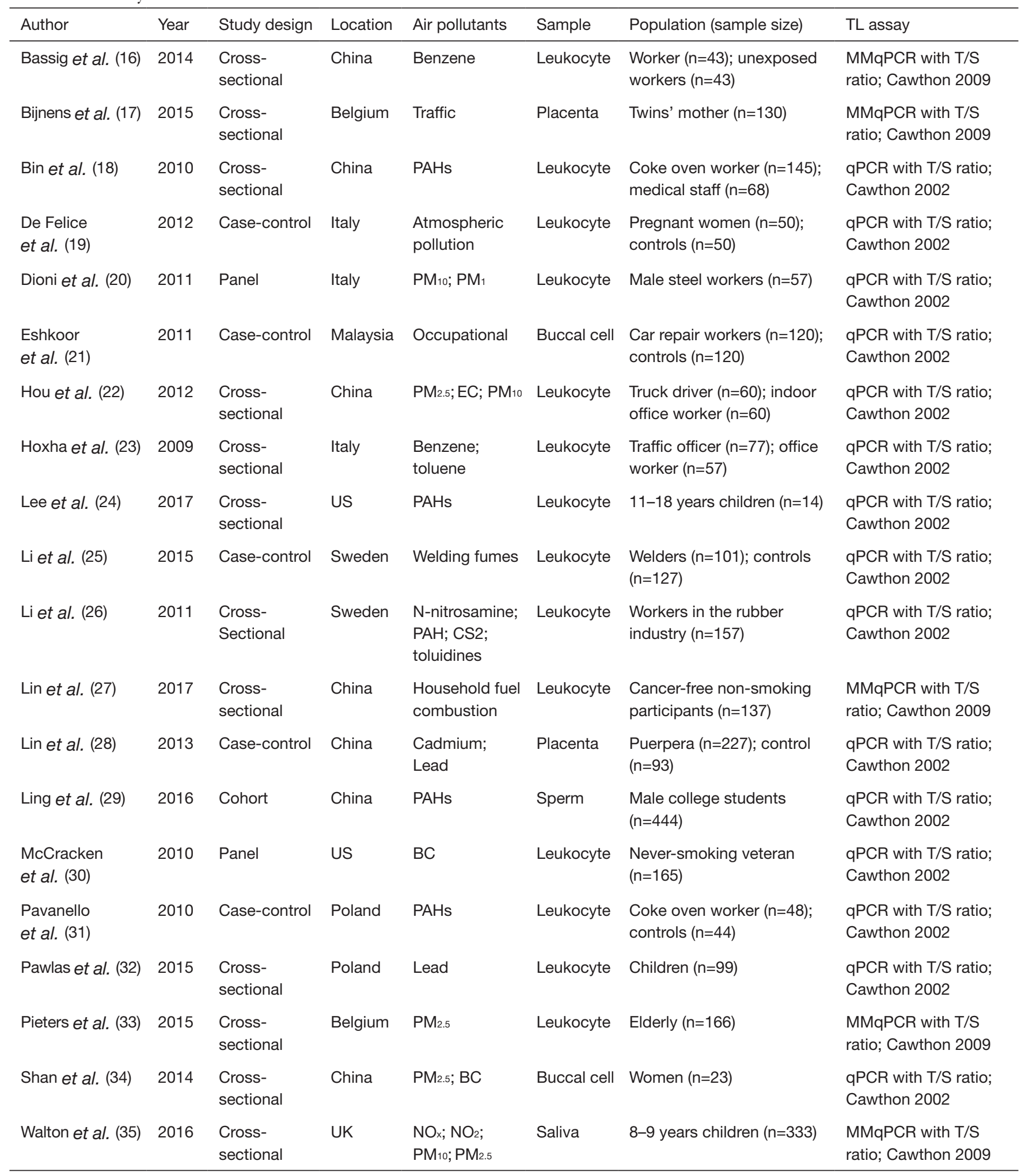

Table 1 (continued) 
Table 1 (continued)

\begin{tabular}{|c|c|c|c|c|c|c|c|}
\hline Author & Year & Study design & Location & Air pollutants & Sample & Population (sample size) & TL assay \\
\hline Wong et al. (37) & 2014 & Cohort & US & $\mathrm{PM}_{2.5}$ & Leukocyte & Male boilermaker $(n=48)$ & $\begin{array}{l}\text { qPCR with T/S ratio; } \\
\text { Cawthon } 2002\end{array}$ \\
\hline Wu et al. (38) & 2012 & $\begin{array}{l}\text { Cross- } \\
\text { sectional }\end{array}$ & China & Lead & Leukocyte & $\begin{array}{l}\text { Battery plant workers } \\
(n=144)\end{array}$ & $\begin{array}{l}\text { MMqPCR with T/S } \\
\text { ratio; Cawthon } 2009\end{array}$ \\
\hline Xia et al. (39) & 2015 & Panel & China & $\begin{array}{l}\text { PM (0.25 to } 10) \text {, } \\
\text { other }\end{array}$ & Leukocyte & Type 2 diabetes $(n=35)$ & $\begin{array}{l}\text { qPCR with T/S ratio; } \\
\text { Cawthon } 2002\end{array}$ \\
\hline Zota et al. (40) & 2015 & $\begin{array}{l}\text { Cross- } \\
\text { sectional }\end{array}$ & US & Lead; cadmium & Leukocyte & $\begin{array}{l}\text { Participants from NHANES } \\
\text { by CDC }(n=6,796)\end{array}$ & $\begin{array}{l}\text { qPCR with T/S ratio; } \\
\text { Cawthon } 2002\end{array}$ \\
\hline
\end{tabular}

BC, black carbon; CDC, centers for disease control; CS2, carbon disulphide; EC, elemental carbon; KORA F4, 4th follow-up of the Cooperation for Health Research in the Region of Augsburg; MMqPCR, Monochrome Multiplex Quantitative Polymerase Chain Reaction; NHANES, National Health and Nutrition Examination Survey; $\mathrm{NO}_{x}$, nitrogen oxides; PAHs, polycyclic aromatic hydrocarbons; PM, particulate matter; qPCR, quantitative real-time polymerase chain reaction; T/S ratio, the ratio of telomere repeat copy number to single copy gene copy number.
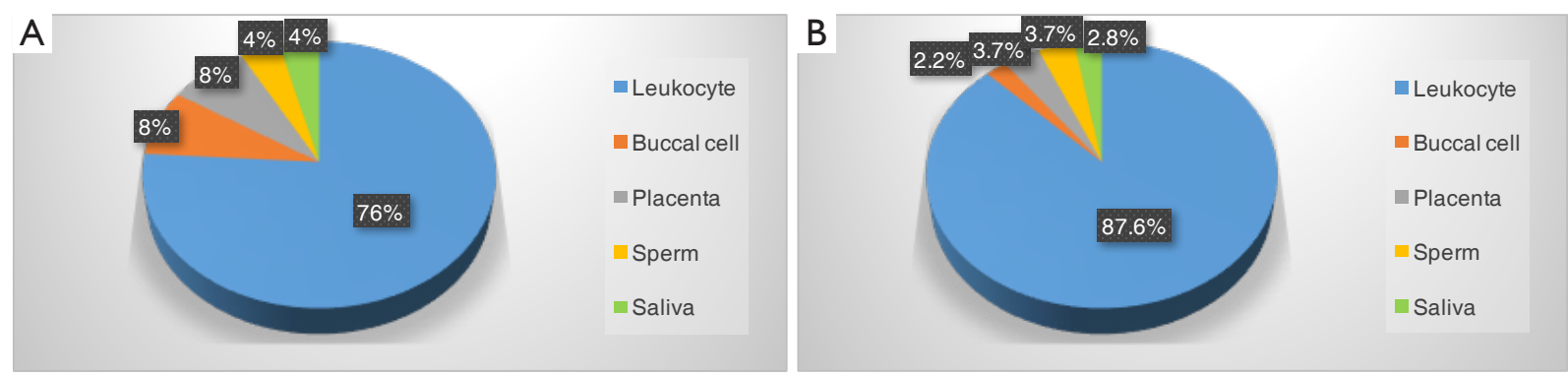

Figure 2 Sources of telomere length assessment. (A) Based on the number of articles. 76\% of studies evaluated leukocyte TL, while buccal cell, placenta, sperm and saliva are the other resources. (B) Based on the number of participants. Among these studies, leukocyte was used for $87.6 \%$ of population, placenta for $3.7 \%$, sperm for $3.7 \%$, saliva for $2.8 \%$ and buccal cell for $2.2 \%$. TL, telomere length.

and air pollution, 15 found shorter LTL with air pollution $(18,19,23-27,30-33,36-38,40), 2$ longer $(16,20)$ and 1 mixed result (22) (Table 2). The one remaining study showed non-significant association between LTL and shortterm exposure to $\mathrm{PM}$ or other gaseous pollutants in type 2 diabetes patients (39). TL from saliva was found to be longer after pollution in children (35). The remaining five studies of placenta $(17,28)$, buccal cells $(21,34)$ or sperm $(29)$ reported shorter TL with air pollution (Figure 3).

Traffic pollutants appear to be associated with shorter LTL $(23,24)$ and placental TL $(17)$. The length of telomeres was reduced with the increase in traffic exposure in these three cross-sectional studies. One used airborne benzene and toluene to indicate the degree of pollution, one study selected ambient $\mathrm{PAHs}$ for vehicle exhaust, and the other used the distance to main road and residential surrounding greenness to estimate exposure. However, inconsistent result was demonstrated in a study where workers were used products containing benzene (16). Similarly, Hou et al. (22) found that truck drivers had increasing TL with personal exposure to $\mathrm{PM}_{2.5}$, elemental carbon and ambient $\mathrm{PM}_{10}$ on the inspection day, while their TL became shorter after 14 days. Interestingly, children from London exposed to traffic pollution had longer TL in salivary cells (35).

Coke oven workers showed shorter TL in both China (18) and Poland (31), where people are widely exposed to PAHs. People who worked in rubber (26), battery (38), boiler (37), welding (25) and car repair (21) environments all showed shorter TL. However, a group of male steel worker had longer TL after three consecutive working days (20). 
Table 2 Main findings of included studies

\begin{tabular}{lllll}
\hline Author & Year & Findings & Changes \\
\hline Bassig et al. (16) & 2014 & Longer TL in workers exposed $>31 \mathrm{ppm}$ of benzene $(1.37 \pm 0.23$ vs. 1.26 $\pm 0.17, \mathrm{P}=0.03)$ & Longer & Shorter
\end{tabular}

to $8.86 \%, P=0.003$ ) longer placental $T L$ at birth

An interquartile increase (22\%) in maternal residential surrounding greenness ( $5 \mathrm{~km}$ buffer) was associated with an increase of $3.62 \%(95 \% \mathrm{Cl}: 0.20$ to $7.15 \%, \mathrm{P}=0.04)$ in placental TL

Bin et al. (18) 2010 Coke-oven workers had shorter LTL $[1.10 \pm 0.75$ vs. $1.43 \pm 1.06, P=0.026, P$ (adjust) $=0.020]$

Shorter

Stratification analysis found shorter LTL in male $(1.08 \pm 0.73$ vs. $1.51 \pm 1.10, F=9.212, P=0.003)$ and non-drinking groups $(0.96 \pm 0.38$ vs. $1.26 \pm 0.46, \mathrm{~F}=6.484, \mathrm{P}=0.012)$

De Felice et al. (19) 2012 TL was shorter in exposed pregnant women (1.27 vs. 3.11, $\mathrm{P}<0.001$ )

Shorter

hTERT mRNA 28\% lower in exposed group (1.123 vs. 1.401, $\mathrm{P}<0.001)$

TL decreased with increasing the proximity from polluted area $(P=0.004)$

Dioni et al. (20)

2011 LTL was longer after exposure $(1.43 \pm 0.51)$ compared with baseline $(1.23 \pm 0.28, P<0.001)$

Longer

Post exposure LTL was positively associated with $P M_{10}(\beta=0.30, P=0.002)$ and $P M 1(\beta=0.29$, $\mathrm{P}=0.042$ )

hTERT expression was lower $(1.31 \pm 0.75$ vs. $1.68 \pm 0.86, \mathrm{P}<0.001)$, but the decrease in hTERT expression did not show a dose-response relationship with $\mathrm{PM}$

Eshkoor et al. (21) 2011 Workers with the mutated genotype (lle-Val, Val-Val) had shorter TL $(0.23 \pm 0.35$ vs. 1.93 \pm 4.53 , $\mathrm{P}=0.008)$, as well as the workers with wild genotype lle-lle $(0.30 \pm 0.67$ vs. $2.65 \pm 7.94, \mathrm{P}=0.019)$

Hou et al. (22) 2012 TL was longer in drivers $(0.87,95 \% \mathrm{Cl}: 0.74$ to 1.03$)$ than office workers $(0.79,95 \% \mathrm{Cl}: 0.67$ to 0.93, $\mathrm{P}=0.001)$

TL increased in association with personal PM2.5 (5.2\%, 95\% Cl: 1.5 to $9.1 ; \mathrm{P}=0.007)$, personal EC (4.9\%, 95\% Cl: 1.2 to $8.8, \mathrm{P}=0.01)$, and ambient $\mathrm{PM} 10(7.7 \%, 95 \% \mathrm{Cl}: 3.7$ to $11.9 ; \mathrm{P}<0.001)$ on examination days

$\mathrm{PM}_{10}$ over the 14 days was associated with shorter TL $(-9.9 \%, 95 \% \mathrm{Cl}:-17.6$ to $-1.5, \mathrm{P}=0.02)$

Hoxha et al. (23) 2009 Adjusted mean LTL was 1.10 (95\% Cl: 1.04 to 1.16) in traffic officers and 1.27 in referents (95\% Cl: 1.20 to 1.35$)(\mathrm{P}<0.001)$

Shorter

Traffic officers had shorter LTL within each age category.

Among traffic officers, adjusted mean relative LTL was shorter in individuals working in high ( $n=45, L T L=1.02,95 \% \mathrm{Cl}: 0.96$ to 1.09$)$ compared to low traffic intensity $(n=32, L T L=1.22$, 95\% Cl: 1.13 to 1.31$)(\mathrm{P}<0.001)$

LTL decreased with increasing levels of personal exposure to benzene $(P=0.004)$ and toluene $(\mathrm{P}=0.008)$

Lee et al. (24) 2017 Inverse linear relationship was found between ambient PAHs exposure and TL. Each $1 \mathrm{ng} / \mathrm{m}^{3}$ increase in PAH456 with a decrease of -0.14 units (95\% Cl: -0.25 to $-0.11, \mathrm{P}=0.01)$ in TL

Li et al. (25) 2015 Welders and controls did not differ in RTL $(P=0.090)$

Shorter

Every working year as a welder was associated with 0.0066 units shorter TL $(95 \% \mathrm{Cl}:-0.013$ to $-0.00053, P=0.033)$

Li et al. (26)

$2011 \mathrm{~N}$-nitrosamines exposure lead to telomere shortening [measured $(\mathrm{n}=60) \mathrm{N}$-nitrosamines $\beta$-coefficient $=-10(95 \% \mathrm{Cl}:-17$ to -1.9$) \mathrm{P}=0.016$; estimated $(\mathrm{n}=157) \mathrm{N}$-nitrosamines $\beta$-coefficient $=-5.3$, (95\% Cl: -9.5 to -0.97$) \mathrm{P}=0.016]$

Table 2 (continued) 
Table 2 (continued)

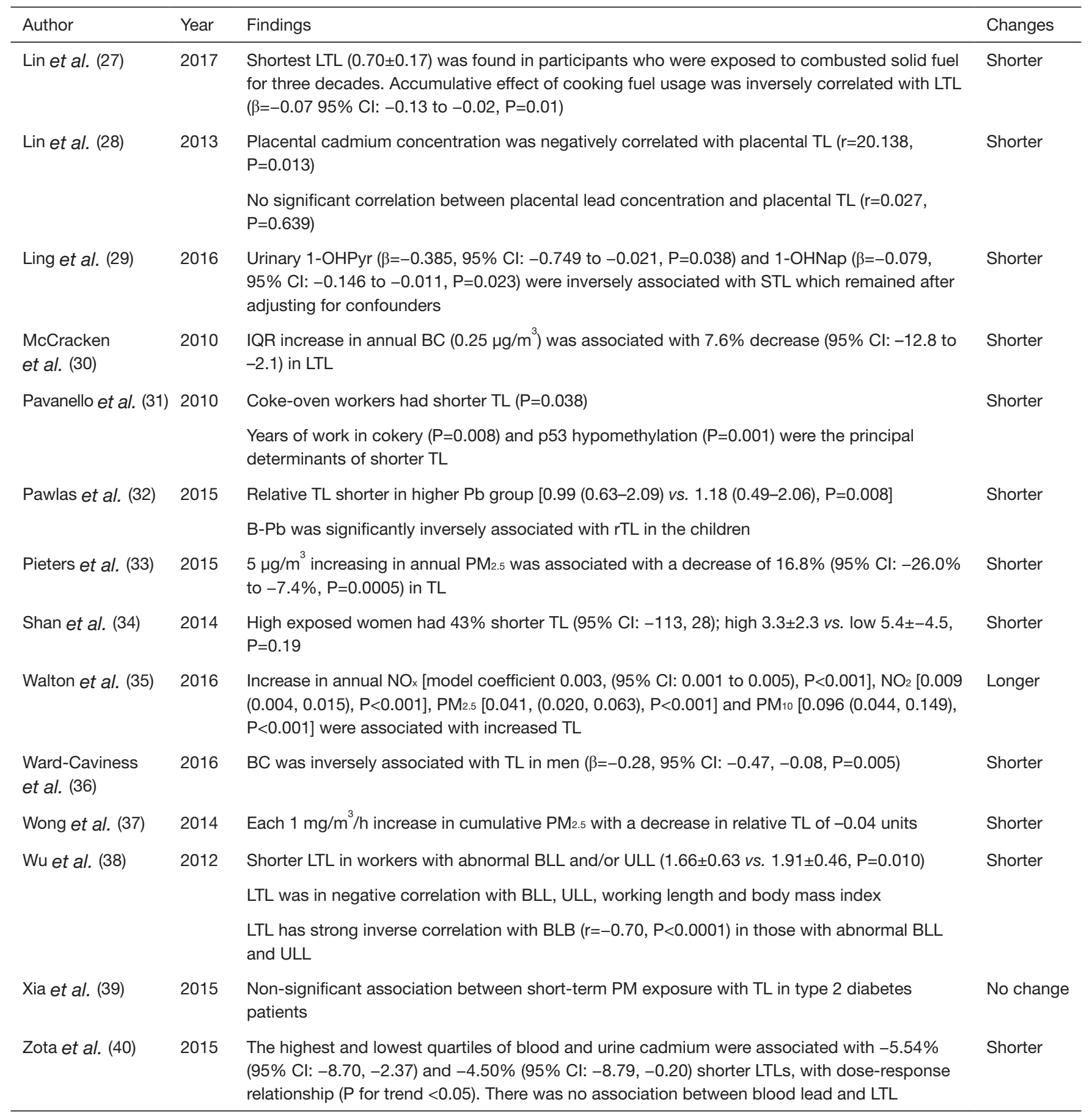

1-OHNap, 1-hydroxynapthalene; 1-OHPyr, 1-hydroxypyrene; 95\% Cl, 95\% confidence intervals; BC, black carbon; BLB, body lead burden; BLL, lead levels in blood; EC, elemental carbon; hTERT, Human Telomerase Reverse Transcriptase; IQR, interquartile range; LTL, leukocyte telomere length; mtDNA, mitochondrial DNA; PAHs, polycyclic aromatic hydrocarbons; Pb, Lead; PM, particulate matter; STL, sperm telomere length; TL, telomere length; ULL, lead levels in urine. 

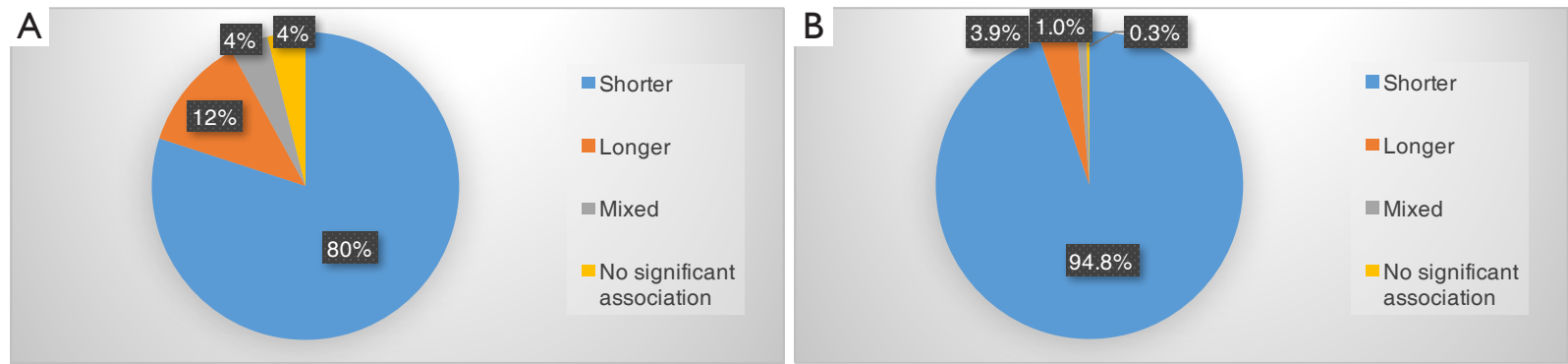

Figure 3 Outcome of telomere length. (A) Based on the number of articles. 20 of 25 studies found association between shorter telomere with air pollution, with 3 longer and 1 mixed result. Remaining one study did not demonstrate significant association between LTL and shortterm exposure to PM or other gaseous pollutants in type 2 diabetes patients. (B) Based on the number of participants. 94.8\% of population in these studies demonstrated the association between air pollution with shorter telomere length. LTL, leukocyte telomere length; PM, particulate matter.

In contrast to short-term exposure, the dynamic change of TL tends to be different when focusing on annual exposure to air pollutants. Pieters et al. (33) demonstrated that annual $5 \mu \mathrm{g} / \mathrm{m}^{3} \mathrm{PM}_{2.5}$ enhancement was related to $16.8 \%$ decreasing in TL of elderly people. Similarly, the TL of elderly men was decreased by $7.6 \%$ with increasing in the interquartile range of annual BC $\left(0.25 \mu \mathrm{g} / \mathrm{m}^{3}\right)(30)$, and this association was stronger among men more than 75 years old. This inverse association between annual BC and TL in male was replicated by another study (36). Pawlas et al. (32) found that children with higher blood lead levels had shorter telomeres. In another study lead was not associated with placenta TL, while placental cadmium concentration was correlated with shorter placental TL (28). Similarly, participants in a US national survey also displayed associations between cadmium and shorter TL while the result was not significant for lead (40). Another study showed that pregnant women who lived near waste landfill sites highly exposed to atmospheric pollution from garbage burning had shorter TL (19). The rubbish in this region has mismanaged involving illegal industrial waste as well as household waste. Women exposed to biomass smoke from cooking which contain $\mathrm{PM}_{2.5}$ and $\mathrm{BC}$ had TL measured from buccal cells. More heavily exposed women had $43 \%$ shorter TL compared with the low exposure group (34). This was corresponding to another finding between exposure to cooking solid fuel and shorter LTL (27). A study of people with type 2 diabetes did not find significant relationship between TL and short term ambient PM or other gaseous pollutants (39).

Ten studies $(19,29,30,32,34-37,39,40)$ were awarded more than seven stars and remaining 15 studies (16-18,20-
$28,31,33,38)$ were graded stars with the number from four to six (Table 3).

\section{Discussion}

This is the first systematic review of studies assessing the association between air pollution and TL. The dominant findings ( $80 \%$ of articles and $94.8 \%$ of subjects) were that that air pollution was associated with shorter TL. While results of studies of leukocyte TL and salivary TL had diverse outcomes, telomeres from buccal cells, placental tissue and sperm all became shorter after exposure. Although all reports used Cawthon's protocol for TL measurements and most evaluated chromosomes from leukocytes, discordant reporting formats did not allow a quantitative meta-analysis.

The telomere is a region of tandem repetitive DNA and protein complexes that cap the ends of chromosome, playing a critical role in maintaining chromosome stability (43). Due to the requirement of 5' to 3' replication and RNA primer, DNA polymerase cannot fully duplicate the end of the chromosome in somatic cells, which leads the telomere shortened after each cycle of the DNA replication (44). TL is approximately 30-100 bp shorter during each cell division process and can act as a senescent marker (45). The components of human telomeres are thousands of TTAGGG nucleotide repeats and protein (46). This special sequence TTAGGG makes telomeres have high content of guanine and are sensitive to oxidative stress (47). The damage caused by oxidative stress can be accumulated and lead to telomere erosion during the lifetime of cell. The shortening of telomere gradually 
Table 3 Quality assessment of included study

\begin{tabular}{|c|c|c|c|c|c|}
\hline Author & Year & Selection & Comparability & Outcome & Number of stars \\
\hline Bassig et al. (16) & 2014 & $\star \star \star$ & $\star \star$ & $\star$ & 6 \\
\hline Bijnens et al. (17) & 2015 & $\star \star$ & $\star \star$ & $\star$ & 5 \\
\hline Bin et al. (18) & 2010 & $\star \star$ & $\star \star$ & $\star$ & 5 \\
\hline De Felice et al. (19) & 2012 & $\star \star \star \star$ & $\star \star$ & $\star$ & 7 \\
\hline Dioni et al. (20) & 2011 & $\star \star$ & $\star$ & $\star$ & 4 \\
\hline Eshkoor et al. (21) & 2011 & $\star$ & $\star \star$ & $\star$ & 4 \\
\hline Hou et al. (22) & 2012 & $\star \star$ & $\star \star$ & $\star$ & 5 \\
\hline Hoxha et al. (23) & 2009 & $\star \star$ & $\star \star$ & $\star$ & 5 \\
\hline Lee et al. (24) & 2017 & $\star \star \star$ & $\star \star$ & $\star$ & 6 \\
\hline Li et al. (25) & 2015 & $\star \star$ & $\star \star$ & $\star$ & 5 \\
\hline Li et al. (26) & 2011 & $\star \star$ & $\star \star$ & $\star$ & 5 \\
\hline Lin et al. (27) & 2017 & $\star \star \star$ & $\star \star$ & $\star$ & 6 \\
\hline Lin et al. (28) & 2013 & $\star \star$ & $\star \star$ & $\star$ & 5 \\
\hline Ling et al. (29) & 2016 & $\star \star$ & $\star \star$ & $\star \star \star$ & 7 \\
\hline McCracken et al. (30) & 2010 & $\star \star$ & $\star \star$ & $\star \star \star$ & 7 \\
\hline Pavanello et al. (31) & 2010 & $\star \star$ & $\star \star$ & $\star$ & 5 \\
\hline Pawlas et al. (32) & 2015 & $\star \star$ & $\star \star$ & $\star \star \star$ & 7 \\
\hline Pieters et al. (33) & 2015 & $\star \star$ & $\star \star$ & $\star$ & 5 \\
\hline Shan et al. (34) & 2014 & $\star \star \star \star$ & $\star \star$ & $\star$ & 7 \\
\hline Walton et al. (35) & 2016 & $\star \star \star$ & $\star \star$ & $\star \star \star$ & 8 \\
\hline Ward-Caviness et al. (36) & 2016 & $\star \star \star$ & $\star \star$ & $\star \star \star$ & 8 \\
\hline Wong et al. (37) & 2014 & $\star \star$ & $\star \star$ & $\star \star \star$ & 7 \\
\hline Wu et al. (38) & 2012 & $\star \star$ & $\star \star$ & $\star$ & 5 \\
\hline Xia et al. (39) & 2015 & $\star \star \star$ & $\star \star$ & $\star \star \star$ & 8 \\
\hline Zota et al. (40) & 2015 & $\star \star \star$ & $\star \star$ & $\star \star$ & 7 \\
\hline
\end{tabular}

The scale contains eight items which has three main aspects: selection, comparability and outcome. Assessment result is demonstrated by the number of stars $(\star)$ the study obtained. A maximum of nine stars can be given for each study.

progresses after each DNA replication cycle and accelerate the cell aging. The most important oxidative stress substance is reactive oxygen species (ROS). ROS easily reacts with nucleic acids, protein and lipids. If the cells do not have enough ability to detoxify these ROS, telomere erosion will happen. Interestingly, Telomere shortening is not an irreversible process. For example, a study of lifestyle intervention demonstrated lengthening of telomeres in the intervention group that persisted 5 years post intervention (48).

In studies included in this review, shorter leucocyte TL was common in people with polluted working or living conditions. Long-term accumulation of air pollution seems to lead to attrition of TL. A cross-sectional study of workers in a battery plant found that body lead burden, measured from $24 \mathrm{~h}$ urine, had stronger inverse association with leucocyte TL than blood lead levels (38). Lead can deposit 
in bone which act as an effective body barrier to decrease the lead in bioavailable blood. There was only one study that did not find an association between short-term PM exposure and leucocyte TL (39). The subjects included in this study were all patients with type 2 diabetes and their telomere dynamics in response to acute stressors such as air pollution may not be generalizable to the wider population.

Every article, identified through our systematic review, used Cawthon's protocol. This technique was first proposed in 2002 and requires tiny amount of DNA to perform PCR for TL assessment (42). Smaller amounts of DNA requirement make this method easily applied to epidemiological studies that usually have large sample size (49). In 2009, Cawthon revised the original version of the method to avoid the methodological shortcoming and named it monochrome multiplex quantitative PCR (41). Due to this development of the method over time, 6 of 20 studies in this systematic review followed Cawthon's 2009 version method $(16,17,27,33,35,38)$, while remaining articles still measured TL through Cawthon's initial method. It seems these two versions of protocol are similar for identified articles in this systematic review and the results are rarely affected by the version they used.

Five types of human tissues were used for TL measurements. A total of 10,568 people in these studies were examined using leukocyte TL, 450 with placenta TL, 444 with sperm TL, 333 with salivary TL and 263 with buccal cell TL. Although TLs in different tissue resources are inconsistent, the attrition rates of TL are similar for adult somatic tissue (50). Leucocytes are widely used for TL measurement because they are easy to extract from blood samples. However, buccal or salivary cells are easier to obtain, the technique is not as invasive, or expensive. The use of placental tissue is limited to research focusing on pregnant women and their offspring. Sperm TL is targeted to investigate male reproductive health.

Air pollutants have various forms including PM, liquids and gases (51,52). The composition and duration of the exposure to air pollutants influences the potential mechanism of action in affecting TL. Many different sources of PM have been shown to induce oxidative stress (53-55), including ambient $\mathrm{PM}_{0.25}, \mathrm{PM}_{2.5}, \mathrm{BC}$, particlebound metals and PAHs. Two studies $(33,37)$ found the inverse relationship between $\mathrm{PM}_{2.5}$ and LTL: one reported with each increase of $1 \mathrm{mg} / \mathrm{m}^{3}$ per hour for cumulative $\mathrm{PM}_{2.5}$ exposure in the past month, TL decreased 0.04 units relatively, while the other found associations with annual average $\mathrm{PM}_{2.5}$ concentrations.
Metals can contribute to telomere disorders in multiple ways. Cadmium can accelerate the production of ROS and disturb the antioxidative response (56). It also prevents the function of DNA mismatch repair systems (57). Other metals provoke the release of inflammatory cytokines (58). One study found longer TL in steel workers exposed to metal-rich PM for 3 working days compared with their TL on the first day before working (20).

Five papers reported the relationship between PAHs exposure and TL of which 3 indicated shorter LTL and 1 with shorter sperm TL. PAHs are a group of organic compounds comprised of multiple benzene rings which can be produced by incomplete combustion (59). Among the studies focused on LTL, Lee et al. (24) chose the level of ambient PAHs with 4, 5 or 6 benzene rings as exposure estimate, while the other two measured urinary metabolite 1-hydroxypyrene (1-OHPyr) to reflect PAHs level. Although 1-OHPyr is regarded as a reliable biomarker (59), it is difficult to determine the specific species of PAHs exposure in these articles and we can't make a quantitative analysis.

Two reports demonstrated longer TL in acute phases after exposure to pollutants. Workers exposed to benzene for 5 separate days during a 2-week period (16), and truck drivers with short-term ambient PM pollution (22) both had longer TL compared with control groups. Little is known about the underlying mechanisms of longer TL in those exposed. Because of the discrepancy to other reports and of uncertainty, further researches are warranted to determine true effect size of air pollution on TL.

Recently, another study has been published after we finished this systematic review (60). It examined the TL from cord blood of newborns and also found shorter TL was associated with prenatal exposure to PAH. The comparison was between two groups of neonates born before and after the closure of the coal burning power plant, which indicated the benefits of reducing air pollution on children's health.

We followed the PRISMA guideline when performing this systematic review, but prospective register with the PROSPERO database of systematic reviews was not successful during data extraction stage. Despite different sources of TL and various air pollutants were obtained through comprehensive search in multiple databases, the heterogeneity among these studies did not allow us to do meta-analysis to make a quantitative inference. All studies were observational and thus have an inherent risk of selection bias. 


\section{Conclusions}

Most of the studies support the association between air pollution exposure and shortened TL. Uniform reporting format would be required to enable combined estimates of the magnitude of the effect size of the impacts of air pollution on TL.

\section{Acknowledgements}

The authors thank Ms Elizabeth Seymour, for her support in systematic review. K Negishi is supported by a fellowship award from the Heart Foundation, which had no role in the preparation of this manuscript.

\section{Footnote}

Conflicts of Interest: The authors have no conflicts of interest to declare.

\section{References}

1. Lim SS, Vos T, Flaxman AD, et al. A comparative risk assessment of burden of disease and injury attributable to 67 risk factors and risk factor clusters in 21 regions, 1990-2010: a systematic analysis for the Global Burden of Disease Study 2010. Lancet 2012;380:2224-60.

2. Lelieveld J, Evans JS, Fnais M, et al. The contribution of outdoor air pollution sources to premature mortality on a global scale. Nature 2015;525:367-71.

3. Brook RD. Cardiovascular effects of air pollution. Clin Sci (Lond) 2008;115:175-87.

4. Brook RD, Rajagopalan S, Pope CA 3rd, et al. Particulate matter air pollution and cardiovascular disease: An update to the scientific statement from the American Heart Association. Circulation 2010;121:2331-78.

5. Brook RD, Franklin B, Cascio W, et al. Air pollution and cardiovascular disease: a statement for healthcare professionals from the Expert Panel on Population and Prevention Science of the American Heart Association. Circulation 2004;109:2655-71.

6. D'Mello MJ, Ross SA, Briel M, et al. Association between shortened leukocyte telomere length and cardiometabolic outcomes: systematic review and meta-analysis. Circ Cardiovasc Genet 2015;8:82-90.

7. Brouilette S, Singh RK, Thompson JR, et al. White cell telomere length and risk of premature myocardial infarction. Arterioscler Thromb Vasc Biol 2003;23:842-6.
8. Fitzpatrick AL, Kronmal RA, Gardner JP, et al. Leukocyte telomere length and cardiovascular disease in the cardiovascular health study. Am J Epidemiol 2007;165:14-21.

9. Samani NJ, Boultby R, Butler R, et al. Telomere shortening in atherosclerosis. Lancet 2001;358:472-3.

10. van der Harst P, van der Steege G, de Boer RA, et al. Telomere length of circulating leukocytes is decreased in patients with chronic heart failure. J Am Coll Cardiol 2007;49:1459-64.

11. Demissie S, Levy D, Benjamin EJ, et al. Insulin resistance, oxidative stress, hypertension, and leukocyte telomere length in men from the Framingham Heart Study. Aging Cell 2006;5:325-30.

12. Said MA, Eppinga RN, Hagemeijer Y, et al. Telomere Length and Risk of Cardiovascular Disease and Cancer. J Am Coll Cardiol 2017;70:506-7.

13. Kelly FJ, Fussell JC. Linking ambient particulate matter pollution effects with oxidative biology and immune responses. Ann N Y Acad Sci 2015;1340:84-94.

14. Moher D, Liberati A, Tetzlaff J, et al. Preferred reporting items for systematic reviews and meta-analyses: the PRISMA statement. PLoS Med 2009;6:e1000097.

15. Wells GA, Shea B, O'Connell D, et al. The NewcastleOttawa Scale (NOS) for assessing the quality of nonrandomised studies in meta-analyses 2009. Available online: http://www.ohri.ca/programs/clinical_ epidemiology/oxford.asp

16. Bassig BA, Zhang L, Cawthon RM, et al. Alterations in leukocyte telomere length in workers occupationally exposed to Benzene. Environ Mol Mutagen 2014;55:673-8.

17. Bijnens E, Zeegers MP, Gielen M, et al. Lower placental telomere length may be attributed to maternal residential traffic exposure; a twin study. Environ Int 2015;79:1-7.

18. Bin P, Leng SG, Cheng J, et al. Association between telomere length and occupational polycyclic aromatic hydrocarbons exposure. Zhonghua Yu Fang Yi Xue Za Zhi 2010;44:535-8.

19. De Felice B, Nappi C, Zizolfi B, et al. Telomere shortening in women resident close to waste landfill sites. Gene 2012;500:101-6.

20. Dioni L, Hoxha M, Nordio F, et al. Effects of shortterm exposure to inhalable particulate matter on telomere length, telomerase expression, and telomerase methylation in steel workers. Environ Health Perspect. 2011;119:622-7.

21. Eshkoor SA, Ismail P, Rahman SA, et al. Does GSTP1 
polymorphism contribute to genetic damage caused by ageing and occupational exposure? Arh Hig Rada Toksikol 2011;62:291-8.

22. Hou L, Wang S, Dou C, et al. Air pollution exposure and telomere length in highly exposed subjects in Beijing, China: a repeated-measure study. Environ Int 2012;48:71-7.

23. Hoxha M, Dioni L, Bonzini M, et al. Association between leukocyte telomere shortening and exposure to traffic pollution: a cross-sectional study on traffic officers and indoor office workers. Environ Health 2009;8:41.

24. Lee EY, Lin J, Noth EM, et al. Traffic-Related Air Pollution and Telomere Length in Children and Adolescents Living in Fresno, CA: A Pilot Study. J Occup Environ Med 2017;59:446-52.

25. Li H, Hedmer M, Wojdacz T, et al. Oxidative stress, telomere shortening, and DNA methylation in relation to low-to-moderate occupational exposure to welding fumes. Environ Mol Mutagen 2015;56:684-93.

26. Li H, Jonsson BA, Lindh $\mathrm{CH}$, et al. N-nitrosamines are associated with shorter telomere length. Scand J Work Environ Health 2011;37:316-24.

27. Lin N, Mu X, Wang G, et al. Accumulative effects of indoor air pollution exposure on leukocyte telomere length among non-smokers. Environ Pollut 2017;227:1-7.

28. Lin S, Huo X, Zhang Q, et al. Short Placental Telomere was Associated with Cadmium Pollution in an Electronic Waste Recycling Town in China. PLoS One 2013;8:e60815.

29. Ling X, Zhang G, Chen Q, et al. Shorter sperm telomere length in association with exposure to polycyclic aromatic hydrocarbons: Results from the MARHCS cohort study in Chongqing, China and in vivo animal experiments. Environ Int 2016;95:79-85.

30. McCracken J, Baccarelli A, Hoxha M, et al. Annual Ambient Black Carbon Associated with Shorter Telomeres in Elderly Men: Veterans Affairs Normative Aging Study. Environ Health Perspect 2010;118:1564-70.

31. Pavanello S, Pesatori AC, Dioni L, et al. Shorter telomere length in peripheral blood lymphocytes of workers exposed to polycyclic aromatic hydrocarbons. Carcinogenesis 2010;31:216-21.

32. Pawlas N, Płachetka A, Kozłowska A, et al. Telomere length in children environmentally exposed to lowto-moderate levels of lead. Toxicol Appl Pharmacol 2015;287:111-8.

33. Pieters N, Janssen BG, Dewitte H, et al. Biomolecular Markers Within the Core Axis of Aging and Particulate
Air Pollution Exposure in the Elderly: A Cross-Sectional Study. Environ Health Perspect 2016;124:943-50.

34. Shan M, Yang X, Ezzati M, et al. A feasibility study of the association of exposure to biomass smoke with vascular function, inflammation, and cellular aging. Environ Res 2014;135:165-72.

35. Walton RT, Mudway IS, Dundas I, et al. Air pollution, ethnicity and telomere length in east London schoolchildren: An observational study. Environ Int 2016;96:41-7.

36. Ward-Caviness CK, Nwanaji-Enwerem JC, Wolf K, et al. Long-term exposure to air pollution is associated with biological aging. Oncotarget 2016;7:74510-25.

37. Wong JY, De Vivo I, Lin X, et al. Cumulative PM2.5 exposure and telomere length in workers exposed to welding fumes. J Toxicol Environ Health A 2014;77:441-55.

38. Wu Y, Liu Y, Ni N, et al. High lead exposure is associated with telomere length shortening in Chinese battery manufacturing plant workers. Occup Environ Med 2012;69:557-63.

39. Xia Y, Chen R, Wang C, et al. Ambient air pollution, blood mitochondrial DNA copy number and telomere length in a panel of diabetes patients. Inhal Toxicol 2015;27:481-7.

40. Zota AR, Needham BL, Blackburn EH, et al. Associations of cadmium and lead exposure with leukocyte telomere length: Findings from National Health And Nutrition Examination Survey, 1999-2002. Am J Epidemiol 2015;181:127-36.

41. Cawthon RM. Telomere length measurement by a novel monochrome multiplex quantitative PCR method. Nucleic Acids Res 2009;37:e21.

42. Cawthon RM. Telomere measurement by quantitative PCR. Nucleic Acids Res 2002;30:e47.

43. Mather KA, Jorm AF, Parslow RA, et al. Is telomere length a biomarker of aging? A review. J Gerontol A Biol Sci Med Sci 2011;66:202-13.

44. Levy MZ, Allsopp RC, Futcher AB, et al. Telomere end-replication problem and cell aging. J Mol Biol 1992;225:951-60.

45. Blackburn EH. Structure and function of telomeres. Nature 1991;350:569-73.

46. Holohan B, Wright WE, Shay JW. Telomeropathies: An emerging spectrum disorder. J Cell Biol 2014;205:289-99.

47. Grahame TJ, Schlesinger RB. Oxidative stress-induced telomeric erosion as a mechanism underlying airborne particulate matter-related cardiovascular disease. Part Fibre Toxicol 2012;9:21. 
48. Ornish D, Lin J, Chan JM, et al. Effect of comprehensive lifestyle changes on telomerase activity and telomere length in men with biopsy-proven low-risk prostate cancer: 5 -year follow-up of a descriptive pilot study. Lancet Oncol 2013;14:1112-20.

49. Montpetit AJ, Alhareeri AA, Montpetit M, et al. Telomere length: a review of methods for measurement. Nurs Res 2014;63:289-99.

50. Daniali L, Benetos A, Susser E, et al. Telomeres shorten at equivalent rates in somatic tissues of adults. Nat Commun 2013;4:1597.

51. Stanek LW, Brown JS, Stanek J, et al. Air pollution toxicology--a brief review of the role of the science in shaping the current understanding of air pollution health risks. Toxicol Sci 2011;120 Suppl 1:S8-27.

52. Lee BJ, Kim B, Lee K. Air pollution exposure and cardiovascular disease. Toxicological research. 2014;30:71-5.

53. Lee $M W$, Chen ML, Lung SC, et al. Increase of urinary concentrations of 8-hydroxy-2'-deoxyguanosine in diesel exhaust emission inspector exposed to polycyclic aromatic hydrocarbons. Int Arch Occup Environ Health 2012;85:273-82.

54. Sauvain JJ, Setyan A, Wild P, et al. Biomarkers of oxidative stress and its association with the urinary reducing capacity

Cite this article as: Zhao B, Vo HQ, Johnston FH, Negishi K. Air pollution and telomere length: a systematic review of 12,058 subjects. Cardiovasc Diagn Ther 2018;8(4):480-492. doi: 10.21037/ cdt.2018.06.05 in bus maintenance workers. J Occup Med Toxicol 2011;6:18.

55. Delfino RJ, Staimer N, Tjoa T, et al. Circulating biomarkers of inflammation, antioxidant activity, and platelet activation are associated with primary combustion aerosols in subjects with coronary artery disease. Environ Health Perspect. 2008;116:898-906.

56. Nair AR, Degheselle O, Smeets K, et al. CadmiumInduced Pathologies: Where Is the Oxidative Balance Lost (or Not)? Int J Mol Sci 2013;14:6116-43.

57. Giaginis C, Gatzidou E, Theocharis S. DNA repair systems as targets of cadmium toxicity. Toxicol Appl Pharmacol 2006;213:282-90.

58. Dong $W$, Simeonova PP, Gallucci R, et al. Toxic metals stimulate inflammatory cytokines in hepatocytes through oxidative stress mechanisms. Toxicol Appl Pharmacol 1998;151:359-66.

59. Ciarrocca M, Rosati MV, Tomei F, et al. Is urinary 1-hydroxypyrene a valid biomarker for exposure to air pollution in outdoor workers? A meta-analysis. J Expo Sci Environ Epidemiol 2014;24:17-26.

60. Perera F, Lin CJ, Qu L, et al. Shorter telomere length in cord blood associated with prenatal air pollution exposure: Benefits of intervention. Environ Int 2018;113:335-40. 
Search criteria

PubMed

$\left(\right.$ telomer $\left.^{*}\right)$ AND ((((particulate AND matter*)) OR (air AND pollution*)) OR (air AND pollutant*))

Results: 62 articles

\section{Scopus}

(((ALL ( particulate ) AND ALL (matter*))) OR ((ALL (air) AND ALL (pollution*))) OR ((ALL (air) AND ALL (pollutant*)))) AND (ALL (telomer*))

Results: 1,426 articles

\section{Embase}

1 telomer*

2 ('air'/exp OR air AND pollution*) OR ('air'/exp OR air AND pollutant*) OR (particulate AND matter*)

3 \#1 AND \#2

Results: 81 articles

\section{Web of Science}

1 \# 1

TOPIC: (particulate) AND TOPIC: (matter*)

Indexes=SCI-EXPANDED, SSCI, A\&HCI, CPCI-S, CPCI-SSH, ESCI, CCR-EXPANDED, IC Timespan=All years

2 \# 2

TOPIC: (air) AND TOPIC: (pollution*)

Indexes=SCI-EXPANDED, SSCI, A\&HCI, CPCI-S, CPCI-SSH, ESCI, CCR-EXPANDED, IC Timespan=All years

3 \# 3

TOPIC: (air) AND TOPIC: (pollutant*)

Indexes=SCI-EXPANDED, SSCI, A\&HCI, CPCI-S, CPCI-SSH, ESCI, CCR-EXPANDED, IC Timespan=All years

4 \# 4

\#3 OR \#2 OR \#1

Indexes=SCI-EXPANDED, SSCI, A\&HCI, CPCI-S, CPCI-SSH, ESCI, CCR-EXPANDED, IC Timespan=All years

5 \# 5

TOPIC: (telomere*)

Indexes=SCI-EXPANDED, SSCI, A\&HCI, CPCI-S, CPCI-SSH, ESCI, CCR-EXPANDED, IC Timespan=All years

6 \# 6

\#5 AND \#4

Indexes=SCI-EXPANDED, SSCI, A\&HCI, CPCI-S, CPCI-SSH, ESCI, CCR-EXPANDED, IC Timespan=All years

Results: 45 articles

\section{Ovid}

1 (pollutant* and air).af.

2 (pollution* and air).af.

3 (matter* and particulate).af.

41 or 2 or 3

5 telomer*af.

64 and 5

Results: 537 articles

Last search: 16 August 2017 